\title{
太湖流域排污权交易优化目标模型 及方案配置研究*
}

\author{
朱德明 1 李洁 2
}

（1:南京农业大学公共管理学院,南京 $210095 ; 2$ :无锡市环境监测中心,无锡 214023 )

提 要 根据江苏省太湖流域水环境与社会经济特征,建立主要污染物排污权交易优化 目标模型；以重点工业污染企业为样本，对排污权交易初始方案实施的预期效果进行定量分 析，提出开展排污权交易制度的政策建议.

关键词 排污权 优化配置 目标模型 定量分析

\section{1 问题的提出}

太湖是我国富饶长江三角洲的核心，人口稠密、经济发达，以“苏湖熟，天下足”闻名 遐迩 “太湖美，美就美在太湖水”成为妇孺皆知的千古绝唱. 随着乡镇企业异军突起、外向 型经济蓬勃发展以及城市化工业化进程加速，太湖流域生态环境不断恶化，成为全国水污 染最为严重的地区之一，成为环境与经济社会发展一切矛盾的聚集点和集中区，严重阻碍 社会经济的可持续发展 ${ }^{[1]}$. 经历“集聚太湖-一零点行动”之后，人们才真正触摸到太湖水污 染防治工作艰难的脉搏.

为实现国务院提出的“太湖水质有所改善，五里湖、梅梁湖水质明显改善”的“十五”环 境目标, 一方面要继续兴建污水处理厂、大力推进水环境综合整治, 削减污染物排放总量, 另一方面需要从水环境资源特点出发, 按照市场供需规律, 积极推行和建立公共资源要素 市场，对现有的排污总量、排污权实行存量调整，提高排污权的配置效率，使稀缺的水环 境容量得到充分利用 $[2,3]$.

\section{2 排污权交易优化目标模型}

排污权交易的首要前提是要确定污染物排放总量，然后才能对这些排污量进行市场 交易. 区域水环境与经济社会可持续发展的系统可分解成三个子系统: 水污染产生系统、 自然水环境自净系统和水污染物处理系统，这三个子系统又分别对应着三个变量，水污染 物产生量 $P$ 、水环境自净能力 ( 水环境容量 ) $P_{1}$ 和水污染物处理量 $P_{2}$.

\footnotetext{
*2004-02-23 收稿; 2004-11-10 收修改稿.朱德明,男,1964 年生,在职博士生.
} 
目前有三种选择途径可以协调水环境保护与经济增长的矛盾，即合理利用水环境容 量、降低水污染物产生量和建设污水处理厂. 在特定的区域单元、一定的自然环境条件下， 可以根据特定的环境质量目标估算出区域内的水环境容量或控制目标容量. 从水环境与经 济可持续发展的角度来考虑，最适的排污总量是，

$$
P=P_{1}+P_{2}
$$

如果排放的水污染物超过一定阈值浓度就会影响人体健康, 破坏自然生态系统. 根据 自然净化能力、阈值浓度以及各污染处理设施的处理能力，政府就可以计算出该地区可能 允许的水污染物排放总量 $(P)$.

如果有 $i$ 个企业在生产单个经济产值 $\left(G_{i}\right)$ 过程中实际排放的污染物量为 $F_{i}$ 在对企 业排污不加控制的情况下，若每个企业随意排放，很可能使

$$
\Sigma F \geq P
$$

若实行污染物总量控制和排污许可证制度，每个企业必须投入治理资金 $C_{i}$ 并实现达 标排放, 减少其排污量. 如果其减少的排放量为 $R_{i}$, 按总量控制目标要求, 减少后的排污 总量不得超过 $P$, 即

$$
\Sigma\left(F_{i}-R_{i}\right) \leqq P \quad 0 \leqq R \leqq F_{i}
$$

每个企业与其生产工艺和技术水平相对应, 有其自己的污染控制成本函数 $C_{F}=f\left(R_{i}\right)$. 如果不存在政府操作成本与企业间交易成本，从成本效率的角度看，我们的目标选择就要 使污染控制的总成本最小化和经济总产值最大化，即

$$
\begin{gathered}
\operatorname{Min} \Sigma f\left(R_{i}\right) \\
\operatorname{Max} \Sigma\left(G_{r} C_{i}\right)
\end{gathered}
$$

此处的控制变量为 $R_{i}$, 限制变量由式 $(3)$ 给定.

式 (3)，(4) 和 (5) 便构成了一个简单的优化控制目标模型. 如果所有企业的污染 控制成本 $C_{i}$ 均是凸函数 (以满足单一优化解), 那么, 根据优化方法, 我们可得到最佳成 本效率控制的必要条件：

$$
\partial f\left(R_{i}\right) / \partial R=\lambda \quad \Sigma\left(F_{r} R_{i}\right)=P
$$

式中, $\lambda$ 为拉格朗日乘数或污染控制的影子价格; $\lambda$ 和 $R_{\mathrm{i}}$ 为非负 $(\geq 0)$.

式 (6) 表明，不论是哪家企业，其控制或减少污染物的边际成本 $\left(\partial f\left(R_{i}\right) / \partial R_{i}\right)$ 均必须与拉格朗日乘数相等，即在边际水平上放松许可证总额限制时所带来的对污染控制 成本的节省额.

现在若政府或环保部门在制定具体的排污权交易总额时，将其分解，分配给各个企 业，企业便可得到初始的基准许可额或交易额 $Q_{i}$ ，使得

$$
\Sigma Q=P
$$

政府在进行许可额初始分配后，便允许各个企业进行许可额的自由贸易（排污权交 易）。每个企业可能将所分配的许可额留给自用，也可以在市场上卖掉；如果排放污染的 企业买许可额比自己控制合算，它也可能去买而不是自己减少排污. 这时，使污染控制成 本最小化的企业所面临的问题便要考虑自己的控制成本 $\mathrm{f}\left(R_{i}\right)$, 权衡购买许可额的花费和 出让许可额的收益.

如果许可额交易符合市场竞争基本要求，市场上的排污许可单价为 $b$, 目标函数可 确定为： 


$$
\begin{gathered}
\operatorname{Min} \sum\left[f\left(R_{i}\right)+b\left(F_{r} R_{r} Q_{i}\right)\right] \\
\operatorname{Max} \Sigma\left\{G_{r}\left[f\left(R_{i}\right)+b\left(F_{r} R_{r} Q_{i}\right)\right]\right\}
\end{gathered}
$$

在交易过程中，企业可以根据自己的污染控制成本函数选择其污染物排放的减少量

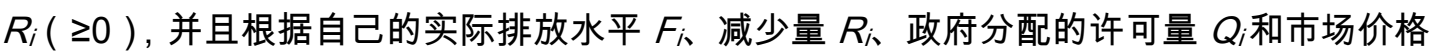
$b$ 来确定许可额的购买和出卖. 如果 $F_{F} R_{r} Q>0$ ，那么该企业就必须在市场上购买额外的排 污许可额 ; 如果 $F_{r} R_{r} Q_{r}<0$ ，该企业则有排污许可余额在市场上出让.

为实现成本最小化和经济总产值最大化, 将式 $(8)$ ，(9)对 $R_{i}$ 求偏导，并令其为零， 便得到方程优化的必要条件：

$$
\partial f\left(R_{i}\right) / \partial R_{F}=b
$$

这说明，企业在进行排污许可市场交易过程中，自己所应采取的污染控制的优化战略 是，污染控制的边际成本与单位排污许可额的市场价格应相等. 例如，有 $A$ 和 $B$ 两家企业， $\mathrm{A}$ 的边际控制成本 $\left(J_{a}\right)$ 比市场价格 $\mathrm{b}$ 高，而 $\mathrm{B}$ 企业 $\left(J_{b}\right)$ 比市场价格 $\mathrm{b}$ 低，即 $J_{a}>b, J_{b}<b$. 企业 $\mathrm{A}$ 就愿意从企业 $\mathrm{B}$ 购买排污许可，从而节省污染控制成本 $b-J_{a}>0$. 对于企业 $\mathrm{B}$ ，也愿 意出让多余许可额而获得治理收益 $b-J_{b}>0$. 这样便实现了在污染物排放总量不增加的情况 下双方均受益的交易. 这种交易直到 $J_{d}=J_{b}$ 时停止. 此时，全社会的污染控制总成本最低， 而社会总产值最高.

\section{3 太湖流域排污权交易效果与评价}

目前太湖流域推行主要水污染物排污权交易制度具有极佳的机遇和条件. 首先，社会 主义市场经济新体制的不断完善，市场机制和经济手段正逐步引入环境管理领域，为具体 实施提供了政策保证 ${ }^{[4]}$. 其次，我国已经制定了一系列有关总量控制、排污许可证、申报 登记等规章制度，为排污权交易奠定了法律基础[5]。第三，长期积累的历史资料，为界定 流域排污权提供保障. 最后, 近几年太湖流域大规模的工业污染源达标排放、城镇生活污 水处理厂建设已使流域内主要污染物排放量大幅度降低，存在一定的“富裕”污染物削减量[6]. 尤其重要的是, 目前太湖流域工业企业在治理污染实现达标排放过程中，地区、行业、规 模与所有制成分之间均存在显著的治理成本差异性（见表 1 ), 这为我们实施这项制度或开 展试点提供了现实可能.

\begin{tabular}{|c|c|c|c|c|c|c|c|}
\hline \multicolumn{2}{|c|}{ 地区差异性 } & \multicolumn{2}{|c|}{ 规模差异性 } & \multicolumn{2}{|c|}{ 所有制结构差异性 } & \multicolumn{2}{|c|}{ 行业差异性 } \\
\hline \multirow{2}{*}{ 一级保护区 } & \multirow{2}{*}{0.22} & 大型－档 & 0.004 & 国有经济 & 0.08 & 纺织 & 0.12 \\
\hline & & 大型二档 & 0.084 & 集体经济 & 0.11 & 化工 & 0.11 \\
\hline \multirow{2}{*}{ 二级保护区 } & \multirow{2}{*}{0.18} & 中型一档 & 0.092 & 合资企业 & 0.26 & 机械 & 0.18 \\
\hline & & 中型二档 & 0.12 & 港澳台企业 & 0.28 & 医药 & 0.31 \\
\hline \multirow{2}{*}{ 三级保护区 } & \multirow{2}{*}{0.08} & 小型 & 0.13 & \multirow{2}{*}{ 其它企业 } & \multirow{2}{*}{0.16} & 轻工 & 0.11 \\
\hline & & 其它 & 0.16 & & & 其它 & 0.07 \\
\hline
\end{tabular}

表 1 太湖流域单位废水平均处理成本单位:亿元/万吨

Tab.1 The average reduced cost of wastewater in the Taihu Lake vally unit: $10^{4}$ Yuan/t

从环境经济学的角度分析，去除水污染物 $(Y)$ 需要投入一定的治污资金 $(X)$, 而且 
两者具有一定的函数关系，即 $Y=f(X)$ ，可见，治理投资的影子价格 $(\partial Y \partial X)$ 应该等于 该企业排污权的市场价格，因此可以用污染物治理的投资效果的差异性替代了排污权交易 的差异性. 为进一步探索排污权交易的内在规律性，研究其实施的可能性及预期效果，以 便于科学指导总量控制与排污权交易活动，笔者以江苏省太湖流域列入国务院限期达标排 放计划的 770 家重点污染工业企业为样本，从中篮选出最有效的 440 家企业的原始数据为 典型，以水污染物为重点，运用优化配置目标模型，在假定交易前提条件和限制因子的前 提下，对最终的四种交易方案在地区、行业、所有制和规模之间的交易结果进行定量预测 分析 (表 2 ).

假定太湖流域维持现有的排放总量，市场交易许可单价 $b$ 为整个流域的平均处理成本 $0.11 \times 10^{8}$ 元/104t，不存在市场交易费用，行业间、规模间、地区间和不同所有制成份间均 可以自由交易流动，我们选择排污量全额交易方案（100\%方案）减半交易方案（50\%方 案) 和少量交易方案 ( $30 \%$ 方案) 三种备择方案，同初始方案 ( $0 \%$ 方案) 的治理投资总额 在地区、行业、所有制和规模之间进行比较分析.

表 2 不同备择方案对产权交易结果的影响

单位:亿元

Tab.2 The effect of different scheme on the transaction result of property right unit: $10^{8}$ Yuan

\begin{tabular}{ccccc}
\hline 交易类型 & $100 \%$ 方案 & $50 \%$ 方案 & 30\%方案 & 零方案 \\
\hline 地区间交易 & 5.40 & 6.08 & 6.53 & 6.67 \\
行业间交易 & 6.44 & 6.56 & 6.60 & 6.67 \\
规模间交易 & 6.61 & 6.64 & 6.65 & 6.67 \\
所有制间交易 & 6.46 & 6.55 & 6.60 & 6.67 \\
\hline
\end{tabular}

从表中可知,进行排污权交易试点,无论是在行业间、地区间、规模间和所有制成份间， 还是不同的交易方案之间，均可以节省处理成本，实现治理投资最小化与削减排污总量、 改善环境质量的“双赢”目标，而且参与交易的范围越广、数量越多，其治理投资总额就越 少，节省的治理成本就越大，取得的效果也就越明显。从交易类型上分析，地区间交易取 得的效果最明显，这主要是由于太湖流域三个保护区之间执行标准上存在显著差异性.

\section{4 加快排污权交易的政策建议}

\section{1 建立和完善排污权制度}

排污权制度建设的目标是应当是所有权“一元化”，使用权“多元化”和处置权“规范化”[7]。 所有权“一元化”系指排污权的所有权由国家实行“国有化”，由国家委托一个行政管理机构来 代表国家行使所有权，充当排污权占有主体，避免由于多个产权主体的同时存在而引起资 源共享所产生的资源破坏. 由于排污权使用主体具有多样性和复杂性，尤其在我国存在多 种经济成份的条件下，实行多元化竞争性经营，搞活排污权使用权，达到环境资源的合理 流转，这就是使用权“多元化”的含义. 处置权“规范化”是指排污权的所有者和经营者，对排 污权的保护、治理、恢复、贮存等各种处置所作的法律约定或行为规范.

4.2 加快排污交易的法规建设 
要加快经济体制改革步伐, 明确将排污权交易纳入经济产权范围, 将排污权与其它生 产要素一样纳入企业产权范围，一并进行体制改革. 要将排污权写入环保法相关的条款之 中，对其产权管理机构、交易程序、价格监督、交易主体限定等作出细化规定，使排污权 的交易、贬存、交换等活动有法可依，避免非法经营和交易.

4.3 确定合理和公平的初始分配方案

综合目前企业承受能力、政府管理水平及市场信息等情况，对排污权采用公开拍卖、 标价出售、免费分配和特殊处置等初始分配形式，合理地将排污权分配到各个经营主体， 避免引发社会利益分配不公、竞争地位不平等等矛盾.

\section{4 积极降低排污权交易费用}

交易费用是影响产权交易活跃程度的最敏感变量. 如果交易成本过多、程序过复杂， 时间过长，甚至高于其获得的预期收益，就会影响交易效率，就可能形成新的成本效率均 衡点，降低排污许可的市场成交量，压抑排污交易的供给与需求。

4.5 建立中介机构，完善产权交易的支撑条件

由专业化、社会化服务机构提供必要的信息服务，通过市场服务寻求信息; 要辟建排 污权的要素市场，调动和激发企业内部治理环境污染的内在动力和活力，依靠经营主体的 理性经济活动来实现环境与经济整体功能的优化，保证排污权机制的高效运行; 要发展环 境金融事业，建立环境银行，开展环境容量及排污量存贷业务; 要完善排污权交易的基础 工作，加强环境容量与总量及排污交易政策的研究。

\section{6 制订促进排污权交易的激励政策}

对努力削减排放总量的排污单位，要从税收、技术、资金等方面予以扶持，并在交易 不活跃时积极向排污单位购买富余排污权，以保护其治理污染的积极性 ${ }^{[8]}$; 对积极出售富 余排污权的排污单位，应保证在其重新需要增加排污指标时优先向其提供并给予优惠等。

\section{7 合理界定排污权交易的对象和范围}

从理论上讲，排污权交易的对象越广、交易范围越大，其优化配置环境资源的作用就

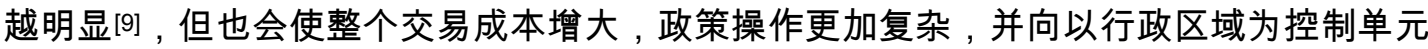
的总量控制制度提出挑战，因此要合理划定排污权交易的对象和区域，使其与区域单元的 环境容量和承载力相适应，实现排污权在整个生态经济区域内的优化配置.

\section{8 积极发挥政府的宏观调控作用}

政府可以在每一笔排污权交易中，利用经济杠杆征收一定比例的排污权作为“交易税”, 来调节产权区域配置. 在排污单位破产或被兼并时,无论其排污权是无偿还是有偿获得的 政府应鼓励排污权作为企业资产进入破产或兼并程序，不应无偿处置排污权资产; 在有些 排污权难以明确、外部不经济性与公共物品难以排除、市场机制难以发挥作用时，应通过 建立各种法律法规，运用行政等手段进行调节; 积极培育排污权市场，提供市场服务信息 调节不合理的资源价格体系，维护市场秩序，促进外部影响的内部化，在创造市场交易条 件和弥补市场失灵等方面发挥作用[10].

\section{9 加快交易试点和推广}

要将排污权交易等工作摆上“十五”以及“十一五”环保计划的重要内容，予以研究和操 作; 将污染物已经有较大幅度削减的地区、基础工作或科研条件较好的地方作为实验区先 行试点，逐步积累经验，探索适合实际的排污权交易制度和政策. 


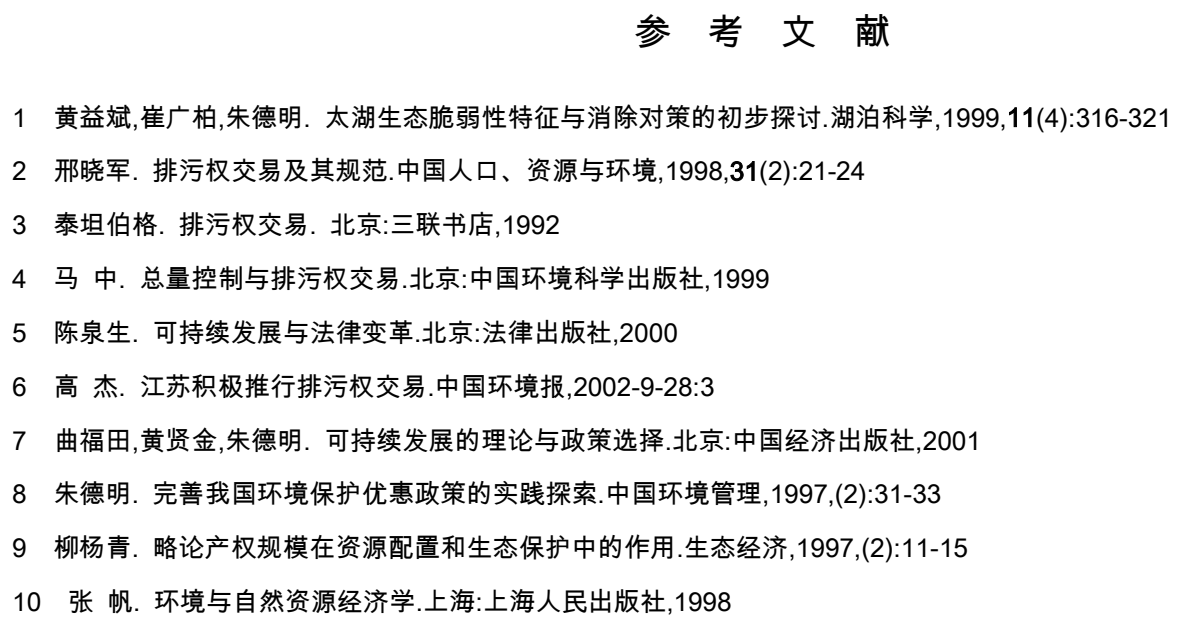

\title{
The Objective Model of Optimized Allocation on Emission Pollution Right and Programe Analysis in Taihu Valley
}

\author{
ZHU Deming ${ }^{1} \&$ LI Jie ${ }^{2}$
}

(1:Nanjing Agricultural University ,Nanjing 210095, P.R.China;2:Wuxi Environmental Monitor Center ,Wuxi 214023, P.R.China)

\begin{abstract}
The objective model of optimized allocation on Emission Pollution Right(EPR) are established on the character of water environment and economics and social in Taihu valley. The transaction result of EPR which emission pollution enterprises in the Taihu Lake valley in Jiangsu Province are analyzed and forecasted as case study, the policy and constitution of EPR are put forward in this article.
\end{abstract}

Keywords: Emission pollution right(EPR); optimized allocation; the objective model; positive analysis 